\title{
Vivências cotidianas do trabalho informal em Brasília
}

\author{
Marcia de M. M. KuYUMJian* \\ Maria T. F. Negrão de Mello** \\ Carolina Cassia Batista Santos ${ }^{\star * \star}$
}

\section{Introdução}

O reconhecimento da desigualdade como processo de fragilização do sujeito social, que pode impelir a uma situação irreversível de exclusão, alude a posições ocupadas por aqueles que estão fora do sistema formal de trabalho e sinaliza para o risco da aventura fora da estrutura reconhecida, devendo, portanto, ser objeto de investigação com o intento de melhor compreender as redes de interdependência construídas entre os privilegiados, os que se encontram em situação de risco e aqueles estigmatizados pelo isolamento social. Pelo cotejo destas situações díspares tornase possível avaliar a fronteira entre as posições e as estratégias de confronto com o indesejável.

A precariedade não é uma situação inédita; é resultado de uma problemática maior, multifacetada e secular, cuja dinâmica é mais veloz na atualidade devido ao crescimento exorbitante

* Doutora em Sociologia, professora do Departamento de História e colaboradora no Programa de Pós-Graduação em Política Social da UnB.

** Doutora em Comunicação Social, professora do Departamento de História e colaboradora no Programa de Pós-Graduação em Comunicação Social da UnB.

*** Mestre em Política Social, professora do Departamento de Serviço Social e chefe do Departamento de Serviço Social da UnB. 
do desemprego. Sua constância histórica desobriga pensar em um comportamento padrão e aponta para o balizamento espaçotemporal que descortina modos peculiares de enfrentamento que passam necessariamente pela esfera econômica, os vínculos societários e a proteção estatal. Frente a tal realidade, o objeto que nos propomos analisar insere-se neste contexto de profundas mudanças e refere-se, mais especificamente, ao mundo do trabalho informal na cidade de Brasília.

A relevância desta temática não se exclusiviza na materialidade do trabalho enquanto locus de criação, de produção e reprodução social, mas ao sentido e valor do trabalho para aquele que exerce uma atividade, bem como para as empresas contratantes e, ainda, para a sociedade como um todo. Mediante este novo comportamento do mercado, como ficam classificadas as várias atividades produtivas e comerciais, que não se agrupam como centrais no processo produtivo hegemônico? Qual a distinção que se estabelece entre atividade de subsistência, emprego, ocupação e principalmente trabalho? As mudanças nas práticas do trabalho associadas à flexibilização das leis trabalhistas conduzem a que tipo de regulação para estas atividades? Como fica o projeto social de emancipação humana através da construção da dignidade e valorização do ser social e, portanto, que trabalha e produz?

Estas questões são importantes como pistas para compreender como os sujeitos em situação organizam seu cotidiano com o propósito de sobreviver, manter o grupo familiar, marcar posição e fortalecer seus elos comunitários. O sentido que cada um destes elementos possui para o trabalhador que atua na informalidade é fruto da sua própria experiência, do seu enquadramento socioeconômico, das transformações objetivas e subjetivas e do glossário de percepções sobre os sujeitos e o mundo. É através destes vestígios do real, materializados nos discursos que se pode apreender a representação social e a alteridade, como processo de significação. Os trabalhadores na informalidade atuam como narradores que, do lugar praticado, constroem discursos que se sobrepõem ao discurso oficial ideológico que homogeneíza o modo de significar o trabalho e a vida. Este é o pressuposto básico desta pesquisa. 
Elucidativa é a noção de Orlandi (2001) sobre a regionalização dos sentidos no corpo do sujeito e na linguagem. Segundo esta perspectiva teórico-metodológica, a atitude é um vestígio de como o sujeito significa, como seu dizer é formulado e estruturado de acordo com as condições, os sentidos e os sentimentos que funcionam como efeitos dos fragmentos que capta do vivido. As modalidades narrativas são, portanto, "flagrantes do espaço urbano", sendo este espaço percebido como sítio de significação, porque é ali que sua realidade se materializa enquanto olhar em movimento, do que se vive e do que se observa na paisagem urbana. A materialidade do mundo do trabalho, sua experiência e seu significado fazem parte deste universo flagrante urbano, e são construídos a partir do lugar de fala de cada sujeito que no confronto com outros vai produzindo sentidos. Desse confronto, significações são elaboradas e se articulam na produção de efeitos. A riqueza desse procedimento analítico, remete, copilando a autora, à imagem da janela que dá a inclinação do corpo e, por conseguinte, produz o gesto necessário para a compreensão da posição do narrador, seu lugar praticado e a materialidade do discurso.

Considerando-se estes dois pontos essenciais, quais sejam, (1) a precarização do mundo do trabalho que coloca o sujeito em situação de risco, e (2) a produção de sentidos a partir dos confrontos discursivos, objetiva-se identificar as representações que estes sujeitos elaboram de si em relação à sociedade e ao próprio Estado.

Este texto é o resultado parcial de um projeto integrado interdisciplinar que articula a Sociologia, a História e o Serviço Social enquanto áreas do saber. O razoável corpus bibliográfico, consubstanciado em teses e livros que consideram Brasília como plano de observação, demonstra a importância das problematizações que afloram de uma cidade monumento. Nesse sentido, a questão focalizada neste texto faz jus à proposta do projeto cujo resultado subsidiará um melhor conhecimento da realidade brasiliense quando se trata do trinômio cidade, cotidiano e cidadania, tendo o trabalho como eixo transversal que recorta as práticas dos grupos.

A trama argumentativa está estruturada a partir da definição de três categorias básicas, quais sejam: 
(1) discussão conceitual de trabalho informal considerando sua vertente sócio-cultural, isto é, lugar onde as representações sociais e alteridades são cotidianamente experimentadas,

(2) a cidade de Brasília, percebida como sítio discursivo que guarda em si a transversalidade do convívio plural e as modalidades narrativas que sobressaem das

(3) práticas cotidianas dos sujeitos em situação, considerandose as entrevistas efetivadas.

Foram efetivadas 180 entrevistas semi-estruturadas nas feiras de Ceilândia, Guará e dos Importados, com ambulantes da Plataforma da Rodoviária e Setor Comercial Sul e, finalmente, com os que atuam nas entre quadras da Asa Norte e da Asa Sul. A reflexão apresentada neste texto trata de parte da análise dos dados obtidos, com destaque para questões tais como: motivações, organização da esfera do trabalho, construção de vínculos sociais e importância do Estado. As análises em profundidade serão oportunamente apresentadas.

\section{Dimensão sociocultural do trabalho informal}

O conceito de informalidade está intrinsecamente vinculado ao conceito de formalidade. O objetivo formal é usado para caracterizar o processo institucional que valida, estrutura, classifica e hierarquiza as diferentes atividades por critérios definidos no âmbito do mercado e também da ordem jurídica. O informal é a confirmação de que, neste procedimento metodológico, há atividades que não se encaixam na ordem classificatória estabelecida. Deste modo, a informalidade só pode ser pensada a partir do desejo social de conhecer, denominar, classificar, hierarquizar e controlar as atividades. A própria denominação é reflexo do procedimento discursivo como imperativo de dominação.

Neste sentido, pensar a dicotomia entre ambas indica que a existência de uma só pode ser apreendida pela existência da outra. Como afirma Freud, vivemos a ambígua condição de 
estabelecer polaridades. Sol e lua se completam. Um permite que compreendamos a existência do outro por oposição, pois se houvesse apenas um único elemento, monolítico e unívoco, sequer seria percebida a existência do mesmo, resumindo-se a um atributo inalienável que não comportaria outra interpretação, outra visão. A existência de um único elemento salientaria, portanto, a função da luz e do calor do sol de modo uníssono e homônimo sem vislumbrar a presença de outra força. Provavelmente mal pressentiríamos a sua presença. O mesmo ocorre com os pares dia/noite, feliz/infeliz, belo/feio, bem/mal, trabalho/não-trabalho, formal/informal e assim sucessivamente. São oponentes em uma mesma dinâmica, portanto, não são excludentes. Pensando nessa indissociabilidade do formal/ informal, Lautier (1994) destaca a inadequação do termo "setor" para diferenciá-las, porque tanto as empresas quanto os trabalhadores podem contratar/desempenhar simultaneamente trabalho formal e informal, sobretudo nos países em desenvolvimento ${ }^{1}$.

O termo formal por definição salienta a condição de evidência ou clareza de algo ou alguém, e aponta para o "ater-se às fórmulas estabelecidas". Destarte, não é espontâneo; é genuíno, preciso e convencional. Na filosofia os termos que saltam são: lei, regra, linguagem própria, contrato, causa, ato, lógica, realismo. Todos apontam na direção de uma concepção construída, da idéia de uma sociedade cuja rotina seja prevista e inscrita nos códigos convencionais. O termo é relativo a forma, ou seja, tem por finalidade dar forma a; formar, permitir que se adquira uma forma aparente. Transpondo para a situação do mercado de trabalho, para que isto ocorresse na construção de um código formal que enquadre as atividades, foi preciso antes de tudo determinar quais atividades são consideradas indispensáveis, quais são dispensáveis e aquelas que devem ser rejeitadas.

Os critérios definidores podem ser rapidamente repassados. No que tange aos critérios morais, crime, tráfico, prostituição, tóxico, roubo, assassinato, dentre outras são atividades recrimináveis, repreensíveis e impugnáveis. Quanto aos princípios que norteiam

\footnotetext{
Para demonstrar a complexidade das realidades sociais, Lautier (1994) utiliza a teoria da Margarida, chamando atenção para a combinação de formalidade e informalidade em uma mesma atividade.
} 
o mercado, considerando-se o grau de desenvolvimento técnicocientífico, há uma tendência crescente a rejeitar atividades que não expressam a lógica produtiva contemporânea, onde modo de produção e relações de produção não seguem de perto o processo de produção modular do capitalismo. Então, cada parte que compõe o social depende de uma rede de procedimentos e formalidade aparente para ser interpretado e recomendado como co-partícipe do processo hegemônico em vigor, sendo legitimado por um discurso que ordena simbolicamente e organiza empiricamente.

Quando se pensa em uma atividade formal existem duas vertentes que precisam ser consideradas: primeiro, a empresa deve ser formalizada através de registro e pagamento de encargos sociais; e segundo, os trabalhadores dessa empresa também necessitam de um contrato que responda às exigências dos vínculos empregatícios, com carteira assinada, descontos de encargos sociais e garantias de direitos trabalhistas, como convencionado na legislação. Essa empresa se constitui como uma tipologia de empreendimento que satisfaz a regulação do trabalho pelo Estado, que funciona como mediador na luta de interesses entre empregador e empregado. Corresponde ao que se poderia denominar de contrato convencional de trabalho.

O conceito de atividade normal deriva da concepção e da construção de um ideário de contrato social no qual tanto empresas quanto trabalhadores são monitorados e controlados pelo Estado para o benefício de ambos: garantia da acumulação e da manutenção da força de trabalho no circuito do mercado de trabalho e do mercado consumidor. Em contraposição a esta tipologia, todas as demais formas de relações de trabalho são consideradas como informais porque, à primeira vista, rompem com o princípio da regulação estatal. Na lógica da regulação estatal, o sistema de fiscalização conduziria a uma inserção forçada destes na formalidade. Assim, seria mantida a unidade pela afirmação do contrato e do controle social. Deste modo, formalidade e informalidade comporiam os dois pólos possíveis de inserção no mundo do trabalho. Um validado socialmente, e o outro marcado pela heterogeneidade e ilegalidade.

O que isto indica? Que havia uma previsão de que o trabalho não formalizado seria pouco a pouco absorvido pelo sistema, restando apenas situações residuais de atividades que não se enquadram no 
modelo capitalista de produção, mas remetem à perseverança de atividades com forte vínculo cultural. Por exemplo, embora a indústria da tecelagem tenha se desenvolvido enormemente, o tear individual e característico do modelo de produção pré-capitalista permanece como uma memória cultural, como uma resistência de grupos que se opõem porque não estão devidamente persuadidos das vantagens do novo modelo, ou ainda, e principalmente, porque no processo de desenvolvimento do novo modo de produção as novas relações de trabalho são consideradas como perda de referência e de autonomia para alguns, por exigir um tipo de conhecimento e domínio de técnicas que, por oportunidade, não estão disponibilizados igualmente a todos.

Estas denominações demarcam a representação sobre legal/ilegal, aceitável/inaceitável, regulado/não-regulado. É uma representação da sociedade estática com uma estrutura social bem equilibrada e previsível. A melhor expressão desse movimento é o entusiasmo em torno do pleno emprego, idealizado no Estado de Bem-Estar Social. Entretanto, à medida que os países do capitalismo central perceberam que o avanço tecnológico e científico contribuía para um modelo produtivo que dispensava mão-de-obra, cresceu a ansiedade sobre as novas condições de serem os trabalhadores novamente absorvidos pelo mercado formal de modo duradouro.

Como resultado, os debates apontavam para a perplexidade com a exclusão social que começa no mundo do trabalho e estendese para as demais esferas da vida. Entende-se aqui por exclusão do mercado de trabalho o processo de não integração no sistema da sociedade regida por relações contratuais lastreadas no pagamento de salários ao trabalho desenvolvido pelos indivíduos considerandose as determinações legais referentes à jornada de trabalho, à atribuição funcional, à qualificação e às garantias trabalhistas resguardadas por leis que incluem $13^{\circ}$ salário, férias, adicional noturno, horas extras, indenizações etc. $\mathrm{O}$ informal é uma vertente do mercado que vem aumentando gradativamente para atender a uma leva de trabalhadores excluídos de trabalhos com contratos formais e excluídos da garantia de direitos trabalhistas e, portanto, de formas estáveis de inserção social.

Segundo Castel (1992), o relançamento do discurso sobre os excluídos e a exclusão social deriva do aumento das desigualdades 
sociais que provocam a acumulação de deficientes econômicos e sociais circunscritos em uma zona inquietante do espaço social. $\mathrm{O}$ crescimento da exclusão e o aumento da distância desta em relação às formas de participação comum na vida social levam ao risco de fratura social. Doravante, multiplicam-se as medidas especiais de intervenção que vão da renda mínima às múltiplas operações de inserção e reinserção sociais. Embora sejam indispensáveis e urgentes, o autor chama a atenção para o perigo de se autonomizar situações limite, conduzindo à perpetuação da exclusão. Neste sentido, Castel (1992) propõe pensar a exclusão como o ponto extremo de um processo em andamento no qual situações extremas, tais como marginalidade, isolamento e pobreza, devam ser relacionadas a situações de vulnerabilidade, precariedade e fragilidade.

A exclusão do mercado de trabalho não pode ser confundida com a exclusão social. Enquanto aquela retrata um quadro de precarização das condições de trabalho, de vulnerabilidade do ser trabalhador e de fragilidade moral do sujeito que trabalha, esta envia a uma situação extremada de absoluta impossibilidade de se reabilitar diante das dificuldades criadas pelas profundas alterações no sistema de produção. Portanto, é útil considerar as três zonas de organização ou de coesão social de Castel como indicativos do grau de integração ou exclusão social:

1) zona de integração que remete às questões de regulação social;

2) zona de vulnerabilidades, considerada zona de turbulência causada pela precariedade das relações de trabalho e pela fragilidade dos apoios relacionais;

3) zona de exclusão, de grande marginalidade e desafiliação que afeta os mais desprovidos de recursos econômicos, de apoio relacional e de proteção social.

O corpus analítico desta pesquisa centra-se especialmente sobre a zona de turbulência que engloba trabalhadores descartados do mercado formal e ainda, senão principalmente, os trabalhadores que historicamente organizaram suas vidas em atividades fora da 
regulação estatal. Isto é, nunca, ou raramente, tiveram uma carteira de trabalho.

Se a globalização econômica desvelou que a produtividade não requer mais, como força produtiva, grande quantidade de mão-de-obra, novas formas de organização dos grupos fora do mercado instituído e legal se mesclaram com aquelas já existentes desde a colonização como saída contra o desemprego e a favor da sobrevivência e da comunidade.

Deste modo, a globalização favoreceu a emergência de formas locais e peculiares de organização do trabalho, constituindo-se mais como o despertar para a pluralidade social e econômica do que a confirmação da sociedade global orientada pela economia. Não é por acaso que Amartya Sen (2001) analisa a desigualdade social enfatizando a pluralidade como decorrente da diversidade humana e das necessidades que variam em função de cada indivíduo, cada grupo familiar ou comunitário. Assim, diversidade e necessidade nem sempre correspondem a critérios econômicos. Certeau (1994) sugere que a realidade, maciça, seja observada de diferentes ângulos, possibilitando que o olhar absorva as nervuras e as fraturas do tecido social derivadas da pluralidade. Para tanto, se faz mister um duplo movimento, compreensão e libertação das amarras epistemológicas que impedem enxergar a riqueza do mundo deslocando o olhar do consumo passivo de produtos para as criações anônimas, nascidas das práticas do desvio, de formas múltiplas de organização que irrompem e proliferam no social.

Não há, portanto, um discurso hegemônico. Qualquer discurso representa apenas uma das construções possíveis em função da pluralidade de experiências e vivências sociais. É neste sentido que optamos pelo termo prisma, por traduzir situações mutantes, de imagens sincrônicas e diacrônicas que se formam pelas modulações dos movimentos presumíveis. Imagem condicionada à idéia do caleidoscópio como invólucro, das figuras que saltam aos olhos nas suas multiplicidades de cores e formas.

Adotando a postura "antidisciplinar" proposta por Certeau (1994), onde a cultura na sua pluralidade é o elemento mobilizador para a transformação, identificamos o trabalho informal, não 
apenas como resultado das mudanças econômicas, mas também, e principalmente, como um dos possíveis prismas dessa realidade. São movimentos compelidos pelas oscilações do mundo externo, bem como pela agitação latente dos gestos e percepções internas. Conhecer é aceitar o inusitado como normal, deixando que as surpresas derivem dos arranjos combinatórios entre esses elementos díspares. Inusitado remete à idéia de excepcionalidade, extraordinário, de singular e único, insinuando o confronto com o desconhecido, do olhar apreendendo algo que lhe é novo, mas não necessariamente inexistente.

Esta breve alusão ao termo conduz à questão: o que é inusitado e para quem? A imagem da informalidade ganha evidência no ordenamento da sociedade industrial e instrumentaliza a bandeira da regulação estatal. Entretanto, é sabido, no plano das práticas cotidianas, que atividades informais são constitutivas da história brasileira, da combinação entre as possibilidades reais e as ações desviantes dos grupos que procuram driblar a ordem ou, como insiste Certeau, ações flagrantes da "liberdade gazeteira das práticas". Essa é uma dinâmica que evidencia, de um lado, as disputas em favor do ordenamento central, da qual deriva o desejo de formalizar e, de outro, a materialidade dessas práticas. Em conseqüência, a polarização formal/informal torna-se inadequada, principalmente porque está ocorrendo um movimento de flexibilização dos contratos formais. Daí decorre outra questão: o movimento atual é o da informalização do formal, ou da possibilidade de se ampliar o conceito de formal de modo a absorver outros tipos de contratos, onde, por exemplo, a palavra tenha valor de contrato?

Uma leitura mais cautelosa, dos empreendimentos e atividades fora do chamado contrato convencional de trabalho, alude à existência de uma gama de possibilidades de organização e desenvolvimento da atividade produtiva que dificilmente poderia ser apreendida em um conceito fechado. O informal deve ser entendido como um campo amplo, difuso e de difícil captura e, portanto, marcado pela heterogeneidade e complexidade. Assim, a idéia da informalidade como espaço da ilegalidade não responde à exigência conceitual porque confunde o trabalhador fora do contrato regular com aquelas atividades que, embora rentáveis, ferem os princípios do elo social, quais sejam, a criminalidade, a prostituição, o narcotráfico. 
Esta percepção leva à definição da informalidade pela articulação de duas concepções. De um lado, aquela que enfatiza sua natureza econômica e cuja definição deriva dos indicadores do IBGE, classificando como atividade informal todas as alternativas de ocupação que não se enquadram no trabalho assalariado regulamentado pelo Estado e que tende a abrigar atividades intersticiais de baixa produtividade, de grande precariedade e forte aleatoriedade (cf. Dalbosco, 2000). Outra, que incorpora a dimensão sociocultural, percebendo o informal como o conjunto de atividades inscritas nas práticas cotidianas que garantem a sobrevivência e a organização que dão a dimensão ao grupo humano comunitário, qual seja, sua disciplina, sua hierarquia, sua rotina e, deste modo, conduzindo ao sentimento de ligação social (Sennett, 1999).

Neste cenário da vida cotidiana são colocados em funcionamento todos os sentidos individuais, tais como capacidades intelectuais, habilidades manipulativas, sentimentos, paixões, idéias e ideologias (Heller, 2000). São gestos e práticas historicamente localizados, como resultado das reformulações das assimilações do passado com impacto direto e irrestrito sobre o momento presente. Segundo Heller (2000), estes são fatos ontológicos fundamentais cuja complexidade está refletida e se baseia na assimilação da realidade e na manipulação das coisas como dinâmica das necessidades e sua satisfação. No seu seio predomina a heterogeneidade no que diz respeito ao conteúdo, à significação ou ainda à importância das atividades desenvolvidas, seja na organização do trabalho, seja na organização da vida privada. Neste processo, os sentidos construídos, os consensos e as polarizações são elaborados e consolidados como estruturas ritualísticas (Maffessoli, 1997). O rito demarca o espaço de atuação de cada fração do social, do instituído e do instituinte (Castoriadis, 1982) e, a distinção entre formal/ informal segue a mesma lógica, é a concretização de estruturas ritualísticas que nutrem e representam diferentes ângulos dos vínculos sociais.

Enquanto as relações formais estão arquitetadas em regras jurídicas desenhadas sobre a concepção universalista de direitos e deveres e, portanto, privilegiando a relação impessoal, o informal possui seus próprios critérios de organização estabelecidos no 
momento em que o contato entre as partes se estabelece, gerando um tipo de solidariedade peculiar. Se no sistema formal a tendência tem sido de uma das partes provavelmente desconhecer as normas do contrato ou mesmo as brechas deixadas na lei, o que conduz à desconfiança de uma das partes, no informal a sobrevivência depende do vigor do contrato de confiança, da garantia da palavra dada.

Por exemplo, enquanto no informal vigora a competição pela conquista e manutenção do cliente, sendo um único cliente importante para a sobrevivência do empreendimento, nas grandes redes departamentais isto tem pouco, ou quase nenhum, impacto. $\mathrm{O}$ núcleo duro da empresa formal se manifesta na impossibilidade de barganha do cliente, flexibilizando apenas as relações trabalhistas, o que conduz a uma rigidez do sistema. $O$ informal favorece a relação de caráter simples que permite um pacto velado de garantia da clientela, sem questionar a procedência do produto, sua garantia e durabilidade. Aceita-se o risco em troca da interação face a face, do preço competitivo e da manutenção dos vínculos sociais. Com isto queremos dizer que o reconhecimento da diversidade humana (Sen, 2001) e do contexto complexo da vida social (Maffesoli, 1997; Morin, 2001) permitem descortinar a mistura entre ordem e desordem, entre regularidade e irregularidade, entre as contradições das ações e os obstáculos que devem ser superados. São práticas que apontam para os consensos e as polarizações consolidadas em códigos e para hábitos e normas segundo o conhecimento disponível. Esta coexistência da heterogeneidade se traduz nas formas como a cidade de Brasília é representada e a alteridade se institui como resultado do comportamento e da experiência dos sujeitos em situação.

\section{Brasília: sítio discursivo}

Se durante os Trinta Gloriosos a idéia da formalização das relações trabalhistas estava sob a égide do fordismo-taylorismo, hoje, a ruptura com aquele modelo tem possibilitado a constituição de novas formas de trabalho. Empresa formal e trabalhador com vínculo frouxo; empresa meio-formalizada e o trabalhador com vínculo frouxo; empresa e trabalhadores não formalizados, os por 
conta própria, prestadores de serviços, trabalho doméstico e outros, formam um bloco de relações de trabalho de difícil leitura jurídica como exige o rigor da lei. As mudanças na forma como a sociedade se organiza e se estrutura, a partir dos movimentos derivados da reestruturação produtiva, instituem um vazio entre o prescrito e o vivenciado, principalmente se considerarmos as especificidades dos núcleos urbanos, dos quais Brasília destaca-se por ter sido uma cidade construída com um propósito político-institucional e cuja espacialidade ganhou na dinâmica cotidiana uma certa autonomia em relação ao arquitetado.

A realidade de Brasília, na atual configuração da divisão social do trabalho, aponta para duas situações distintas: o funcionalismo público sustentáculo do sistema administrativo, e a informalidade derivativa da expectativa por oportunidades de trabalho e moradia. Uma realidade informada por duas necessidades distintas, o funcionamento da máquina estatal e a busca de solução para condições insustentáveis de vida. Há um imaginário forte, a idéia do eldorado, das possibilidades ilimitadas, da concentração da elite política e da média salarial que extrapola a média nacional.

O discurso que informa sobre esta cidade centra-se sobretudo na proximidade com o poder, no benefício da ordem institucional mesmo que desviante. Fica aberta a chance de ter acesso a algum político e sensibilizá-lo para a fragilidade individual e, quem sabe, a sorte de ter um emprego garantido. Às vezes esse imaginário é informado pelo sucesso de algum vizinho, amigo ou parente, que afirma orgulhosamente os benefícios dos contatos com algum "figurão", dando-lhe mais status, mais crédito e mais respeitabilidade no seu círculo de convívio cotidiano. Possibilidade estimulante que associada à facilidade de se adquirir um lote doado, fortalece a vinda incessante de levas de migrantes. Promove-se assim o crescimento descontrolado da periferia de Brasília (Paviani, 1989).

O desenvolvimento e a consolidação de núcleos urbanos ferem o plano arquitetônico inicial, conduzindo a uma agressiva segregação espacial principalmente pelo fato de os núcleos habitacionais não dispensam de autonomia na geração de emprego. O Plano Piloto permanece como o referencial empregatício. O movimento espacial é, portanto, bem peculiar: de um lado o incremento populacional produz assentamentos irregulares, segregados espacialmente 
principalmente pelo papel do poder público de regularizar e transferir esses assentamentos para localidades mais longínquas do centro urbano, instituindo a periferização; de outro, a busca do emprego pela movimentação diária desses segregados para o centro.

Este processo de periferização afeta a arquitetura da cidade, com congestionamentos cada vez mais intensos, visto que das oito cidades satélites iniciais, o Distrito Federal conta hoje com 19 regiões administrativas, totalizando por volta de 1,9 milhões de habitantes. Situação agravada com a gestão Roriz, iniciada no ano de 1990,devido à sua política populista, que estimula as invasões com promessas de doação de lotes às populações de baixa renda (Piubelli, 2001).

O cinturão de pobreza que vem crescendo em volta do Plano Piloto decorre de políticas protecionistas ao próprio plano, patrimônio da humanidade, bem como em conseqüência da especulação imobiliária nas áreas nobres da cidade. Com isto, a expectativa social original foi rapidamente substituída por parâmetros econômicos que não só empurraram as populações de baixa renda para a periferia, como também produziram nestas a percepção de que as expectativas de sobrevivência estariam por conta da sua capacidade de adaptação. São estes que engrossam as fileiras de desempregados no Distrito Federal.

Conforme dados da Codeplan, a taxa de desemprego anual passou dos 15,7\%, em 1995, para 19,4\% da PEA em 1998, totalizando 167 mil pessoas desempregadas. O grupo formado pelas regiões administrativas (RAs) de Brazlândia, Ceilândia, Samambaia, Paranoá, São Sebastião e Santa Maria é detentor dos maiores índices de desemprego, com taxa de $25,5 \%$ da PEA em 1998, sendo praticamente o triplo da verificada nas RAs de Brasília, Lago Sul e Lago Norte, de $8,6 \%$ da PEA. Nas RAs de Gama, Taguatinga, Sobradinho, Planaltina, Núcleo Bandeirante, Candangolândia, Guará e Cruzeiro, a taxa de desemprego foi de $18,3 \%$. O crescimento do desemprego ocorre não pela perda de postos de trabalho, como tem ocorrido com a maioria das regiões metropolitanas, mas pelo expressivo aumento da procura de trabalho, pelo impacto vegetativo e pelos efeitos migratórios. Segundo Bursztyn e Araújo (1998), o migrante não encontra um modo de 
se inserir nos circuitos institucionalizados de habitação, emprego e renda da cidade, tornando-se:

protagonista de um curioso e perverso fenômeno: o da convivência, no mesmo espaço e tempo, com uma outra população, aquela que pertence ao universo formal, institucionalizado, da cidade. São dois mundos bem diferentes, que possuem interfaces, que se percebem reciprocamente de forma muito particular: uns, como objeto de geração de sustento; outros, como almas penadas, que perambulam pelas ruas, confundindo-se com o lixo ou com diversas formas de ameaça à segurança. (Bursztyn e Araújo, 1998, p. 33-34.)

A ocupação espacial, portanto, deriva da construção de núcleos articulados por sentimentos que corroboram para o processo de construção da identidade do grupo em função de sua trajetória de vida (Firey, 1974). Para aqueles que carregam o peso da migração e da precariedade, o território urbano tem função precisa: apropriação do espaço para atender interesses do próprio grupo, desconsiderando os interesses das localidades centrais. Há, conseqüentemente, uma conexão histórica entre tais sentimentos e a área em que estão presentes estes grupos. Estas localidades possuem identidade própria com projeção espacial de distribuição de bens e serviços e de produção que não passam desapercebidas aos olhos das camadas sociais de baixa renda (periferizada). Ocupar estes espaços expondo seus produtos sem constrangimento é uma prática cotidiana de difícil controle.

O povo em situação marginal sabe que não pode participar do processo de consumo capitalista, haja vista a segregação espacial e social que os separa dos centros de consumo, aprendendo, em virtude disso, como durabilizar os seus objetos e como se beneficiar ou criar um mercado de fácil acesso físico, bem como com preços competitivos que permitam o consumo de bens, mesmo que de qualidade suspeita. Há um elemento viabilizador que constitui um conjunto de forças entre os processos sociais e a organização espacial, o que permite a existência de localizações, re-localizações e permanência de atividades e população sobre o espaço urbano.

O traçado da cidade, sua estrutura física e arquitetônica e sua dinâmica econômica não favorecem a ampliação de postos de trabalho compatível com a demanda populacional, que não cessa 
de aumentar porque não há como evitar o processo migratório. Com isto, a opção ou possibilidade tem sido a informalidade.

No que se refere à renda, estudo elaborado pela Pesquisa de Informações Sócio-Econômicas das Famílias (PISEF), ${ }^{2}$ mostra, por exemplo, que a renda familiar para o Lago Sul é de 65,76 salários mínimos (SM), no Lago Norte, cerca de 52,7 SM, enquanto, em disparidade, Riacho Fundo, Gama, Samambaia, Ceilândia, Brazlândia, Planaltina, São Sebastião, Santa Maria, Recanto das Emas e Paranoá formam um conjunto cuja renda familiar varia entre 9,81 a 4,6 SM. A questão residencial influencia diretamente nas relações sociais, no processo de interação social, e na possibilidade de ascensão social, em virtude do acesso diferenciado devido à desigualdade de renda real. À medida em que tecemos a discussão, torna-se mais clara a relação direta entre este processo de segregação e a inserção no mercado de trabalho.

O que desponta deste quadro situacional é como sua materialidade está informada por diferentes dimensões discursivas. De um lado, prevalece o discurso oficial sobre a cidade monumento, a cidade política, a cidade arte, a cidade padrão de consumo. De outro, o discurso dos homens e mulheres comuns que organizam suas vidas pelas possibilidades de, circulando nas esferas privilegiadas, auferir ganhos financeiros e sociais. A profanização espacial ganha vivacidade nos gestos e movimentos das camadas de baixa renda que, na banalidade cotidiana, se apropriam, deformam e transformam os espaços.

Assim, pensar criticamente a realidade e a forma como a segregação se consolida passa pelas operações de distribuição espacial. Esse conjunto heterogêneo, como salienta Paviani (1989), decorre da separação espacial do Plano Piloto, das cidades-satélites e favelas, ditas invasões, e ainda da periferia goiana funcionalmente vinculada à Capital Federal. Todos são fragmentos do Distrito Federal, que deixam expostos no centro da capital, os sentidos que constroem de si, da cidade e de seus habitantes. E, ao mesmo

2 Disponível em: <http:/www.codeplan.df.gov.Br/pesquisas/dpg_episef.html>; acessado em: 10 ago. 2001. 
tempo, são a expressão mais viva de um Brasil que, provavelmente, a capital gostaria de não ser a representação.

Flagrantes de um real, enquanto as mal equipadas cidadessatélites são o lugar de moradia das camadas de baixa renda, o Plano Piloto detém importância e mantém a oferta de empregos, em torno de $60 \%$, sobretudo os melhor remunerados. Ademais, constatase a elevação dos custos sociais ocasionada pelo distanciamento existente entre local de residência, trabalho e lazer, principalmente pelo fato de que, de modo geral, a periferia não possui condições para reter, nela própria, mão-de-obra e usuários de serviços urbanos.

O discurso oficial, que vocifera contra a banalização do espaço público do Plano Piloto, é contraposto pelo discurso silenciado dessa massa humana que, cotidianamente, ocupa os espaços, grita seus preços, atravessa a rua com suas quinquilharias, monta barracas, institui um comércio cuja marca é a provisoriedade, seduz transeuntes, improvisa refeitórios e lavatórios, deixa seus cheiros exalarem sem pudor pelas praças, naturaliza gestos impuros, consola ou castiga crianças, cochila, discute, coça, bochecha, invade a passarela. É uma "liberdade gazeteira" que contagia e contamina. E a passeata dos "homens sérios", nos seus ternos escuros pouco a pouco perde seu brilho pelo magnetismo do que o povo faz no cotidiano. Esta leitura crítica da realidade não recusa o cotidiano, antes o coloca no centro das análises visto serem essas práticas carregadas de conteúdos culturais e valorativos que informam e nutrem a realidade (Lessa, 2000).

Brasília não é uma cidade apropriada a flaneries. Suas longas distâncias, seus descampados, sua ausência de esquinas e becos, seus edifícios construídos em blocos apartam e isolam as pessoas. Os extremos das classes sociais não se tocam, vivem em espaços desconexos cujo vínculo é criado pela racionalidade esquadrinhada do traçado da cidade que permite o descortinar do previsível. A interação dos homens que habitam o coração da cidade é mais intensa com a natureza e o concreto do que com o murmurinho do populacho. A cidade abriga a exuberância não visível da elite política, protegida nas muralhas de vidro dos seus escritórios ou atrás dos vidros dos carros blindados. Ao mesmo tempo, abriga as práticas corriqueiras e a espontaneidade dos gestos banais dos indivíduos 
que se materializam nas praças, nos jardins, nas calçadas e ruas. É essa dupla organicidade, do comportamento ordeiro e asséptico da elite e da confusão e astúcia dos homens comuns, que informa como as áreas são segregadas entre si, marcando e ritmando o status e os laços sociais daí derivativos. Assim, a diversidade de condições de cada grupo social aparece desde o local de moradia, ambiente de trabalho, até o modo como se apropriam dos espaços públicos. Uns transitam, outros ocupam e constroem lá seus laços sociais.

Os trabalhadores fragilizados tendem a ser isolados pelo postulado geopolítico do polinucleamento, que tanto serve aos grupos dominantes, expressão maior da fragmentação da cidade. Os núcleos são múltiplos, distantes, dispersos, desencorajando as pressões populares. Enfim, o esparramamento urbano favorece o controle geopolítico, atenuando os ímpetos das massas oprimidas e reivindicantes. Mas a invasão diariamente renovada do centro da cidade cria uma nova imagem, de discursos que afloram e flagram a intensidade da trama social, plural e desigual.

São discursos elaborados de diferentes localidades, com diferentes intenções que sinalizam para a complexidade da vida e o reconhecimento de que vigora uma lógica de conhecimento da realidade. Os movimentos e as contradições que emergem da cidade são frutos do comportamento humano que extrapola ao projeto arquitetônico. As pessoas vão imprimindo sentidos, ambivalentes e contraditórios, nas estruturas retilíneas da cidade, fazendo a história e dando visibilidade às relações simbólicas como recentramento do território. Este recentramento não significa um fechamento hermético para com o outro, é um movimento de atração e repulsão que conduz à "aprendizagem de valores culturais, de relações de amizade, de hospitalidade, de generosidade, coisas que delimitam bem as formas de solidariedade constitutivas das sociedades" (Maffesoli, 1996, p. 99). A comunicação e a elaboração de um espaço de trânsito constituem-se como os dois principais fatores de organização do trabalho. A improvisação toma o lugar da tradição cultural local e, ao mesmo tempo, permite a combinação de tradições diversas trazidas na bagagem de cada um, objetivando construir um sentido e uma inspiração para a nova experiência. Um ponto de ancoragem, um porto seguro. Assim, a cidade se constitui em cadinho de 
possibilidades múltiplas das quais não escapam recordações de alhures e de desejo de reconstruir o antigo ambiente neste novo contexto social, restaurando um universo simbólico sincronizado com o dos demais habitantes.

O que se retira desta reflexão é a desigualdade do espaço urbano no que se refere ao acesso aos recursos básicos com diferentes locais de divisão de atividades. É neste espaço que diversos grupos sociais vivem e reproduzem-se, envolvendo o cotidiano e o futuro, além de crenças, valores, mitos, utopias e conflitos da sociedade de classe. Ainda, este espaço, é cenário e objeto das lutas sociais que visam ao direito à cidadania.

Assim, o trabalho em Brasília apresenta-se como uma complexa espacialidade abalizada por ambientes desiguais que, simultaneamente perversos e funcionais, reproduzem cidadãos desiguais.

\section{Construindo sentidos - a fala dos trabalhadores informais em Brasília}

A informalidade tem importante papel enquanto locus de institucionalização de representações sociais, inaugurando formas alternativas de sociabilidade. Incorpora atividades diversas e mantém contato com os segmentos formais. Possui mecanismos de entrada e permanência e de reconhecimento e utilidade, ensejando um amplo manancial de códigos e simbolismos. Estes são fatores que revitalizam a informalidade, reduzindo o sentimento de marginalidade e abrigando trabalhadores que tentam cotidianamente enganar a insegurança e a aleatoriedade.

Ali podemos apreender os gestos, as relações e as atividades rotineiras. O espaço do banal faz emergir a construção de mundo com toda a dramaticidade, ambivalência e sonhos, conferindo à informalidade uma renovação constante que dificulta programação política e econômica. Esta renovação está inscrita nas práticas experimentadas cotidianamente, onde o inesperado e a rotina se entrecruzam. 


\section{1) A rotina}

Há semelhanças na rotina dos trabalhadores informais que este tipo de inserção no mercado oferece. O cotidiano é permeado pela insegurança sempre presente, causada pela contingência do mercado. São inúmeros os fatores que se interpõem na ordem do trabalho. Até o clima torna-se um limitador, pois em dias de chuva as atividades não são iniciadas, ou encerram-se mais cedo, comprometendo o ganho diário, que não pode ser projetado por um período mais longo, como, por exemplo, um mês. É também permeado pela incerteza de um futuro bom, com direitos garantidos, tais como aposentadoria e plano de saúde. Embora não controlem as condições físicas das atividades e sequer as fragilidades diárias, insistem: "é melhor um emprego incerto do que nenhum", informa um dos entrevistados.

São trabalhadores que têm experiências diferentes de vida, muitas vezes sofridas, pois muitos deles não possuem nem o primeiro grau completo. $\mathrm{O}$ que os agrega é a idéia de trabalho como a principal prioridade. Em segundo lugar, encontra-se o lazer apreendido por eles como o tempo dedicado à família e à casa. $\mathrm{A}$ educação ocupa, geralmente, o último lugar, porém não é por sua pouca significação, posto que todos acreditam na sua positividade, mas devido ao adiamento de uma realização em função das demais demandas reprimidas, como a garantia de qualidade de vida familiar. Isto revela que, mesmo estando na informalidade, o trabalho requer uma organização não só do feirante mas de toda a estrutura familiar. Tempo, dedicação, disponibilidade, afazeres domésticos, responsabilidade pelos dependentes, são diuturnamente negociados, gerando um sentimento de improvisação da própria vida.

\section{2) Organização do trabalho}

Quanto à organização do espaço de trabalho e as relações de trabalho, aproximadamente $70 \%$ dos entrevistados são donos de seus próprios negócios. Geralmente pagam uma taxa para a administração da feira que oferece uma infra-estrutura básica, caracteristicamente com asfalto, estacionamento, banheiros, área cercada, tendas e vigilância, o que confere um status superior em relação ao ambulante que está presente na periferia deste 
espaço semi-instituído. Vigora um acordo tácito entre governo e trabalhadores informais de mútua tolerância. Embora haja alguma infra-estrutura, as queixas derivam das más condições de trabalho, destacando-se o calor excessivo devido ao material de cobertura das barracas, a poeira e o acúmulo de lixo.

A grande maioria destes trabalhadores (75\%) nunca trabalhou com carteira assinada, portanto não passou pela socialização do mercado formal. Ao que tudo indica, preserva-se uma prática familiar, geralmente oriunda de atividades rurais com fortes tendências informais. Assim, são facilmente identificadas, neste segmento, as pessoas cuja história familiar, por gerações, se construiu fora do mercado formal. $O$ interessante é que há um certo ressentimento quanto à ausência de estabilidade da carteira de trabalho e, paradoxalmente, um alívio de se estar fora do controle de um patrão percebido como um explorador em potencial.

3) Representação

A atividade econômica exercida na informalidade constitui-se como um diferencial dos segmentos formalizados e a representação é expressa na nomenclatura utilizada. Enquanto no formal coloca-se em destaque a idéia de profissional, no informal há a confluência de um sem número de opções que ganham muitas vezes conotação jocosa, mas que servem para especificar/distanciar dos segmentos formalizados.

O envolvimento com a informalidade insere-se na percepção de cada um sobre o direito e a oportunidade de se estabelecer um negócio próprio, de ser seu próprio patrão, de fazer a sua vida seguir da forma como deseja. Além disso, esses trabalhadores atribuem ser a atividade prazerosa e aceitável: poder administrar o tempo, definir o próprio trabalho, organizar a jornada de trabalho, contabilizar o lucro do dia-a-dia, tomar decisões e alterá-las em função do andamento do empreendimento ou das circunstâncias imediatas. Os planejamentos de longa duração são substituídos pelos de curta duração, entram na lógica das resoluções imediatas, decorrentes de avaliações constantemente colocadas na mesa e repensadas segundo as exigências e necessidades momentâneas. $\mathrm{O}$ eixo da necessidade muda em função da circunstância. É imperativa a imediaticidade das decisões na supressão de problemas e obstáculos. 
Como o informal é pensado em contraposição ao formal, e como os trabalhadores informais possuem como referência da formalidade o funcionário público, a auto-imagem é também construída a partir daquilo que identificam como positivo e negativo na formalidade. A opinião corrente é que o funcionário público tem uma situação estável e segura, mas, ao mesmo tempo, de muita subordinação. O salário fixo mensal associado à durabilidade no emprego e, no final da linha, uma aposentadoria alentadora são os pontos fortes do trabalho formal. Para estes trabalhadores somente o serviço público é capaz de promover status. Entretanto, o concurso público, que exige uma certa formação educacional, é um limitador. Os demais trabalhos formais, nas empresas privadas, tendem a ser mal remunerados, pouco valorizados, instáveis e precários, não conduzindo a um estímulo ao trabalhador para a formalidade.

\section{4) Renda}

Dentre os entrevistados, $70 \%$ afirmaram ser a atividade na informalidade a única fonte de renda e garantia de sustentação familiar. Trinta por cento destes informaram ter uma renda combinada, por exemplo, um membro da família tem uma renda segura vinda da formalidade a qual é completada pelo trabalho de outro membro atuando na informalidade. Enquanto o primeiro garante a manutenção do grupo, o segundo abre a perspectiva de financiar a mobilidade social para um eleito do grupo, geralmente um dos filhos, garantindo boa escola. Outra possibilidade é o trabalho formal ao longo da semana e a informalidade nos finais de semanas ou no período noturno, como alternativa aos baixos salários estruturais vigentes no país.

De modo geral, a maioria dos entrevistados afirma que a renda oriunda da informalidade é suficiente para suprir suas necessidades básicas e despesas com saúde, lazer, alimentação, transporte e moradia.

Complementarmente, as mulheres informaram que, além daquela atividade, são também representantes de agências de produtos cosméticos, fazem as tarefas domésticas para economizar nas despesas da casa e ainda estudam ou fazem faxinas aos finais de semana, ou aceitam encomendas de doces e quitutes. Inquestionável é a dupla e senão tripla jornada de trabalho feminino. 
5) Mulheres

A feira é o reino das mulheres. Lugar seguro, de fácil acessibilidade, geralmente respaldado política e socialmente, com circulação constante de familiares para o abastecimento da casa. Há o predomínio de mulheres na faixa etária de 31 a 50 anos (55\%). As jovens entre 17 e 20 anos correspondem a 10\% das feirantes e são, geralmente, filhas dos proprietários, que auxiliam a família nos negócios, ou assalariadas em situação temporária. Há ainda um número razoável de mulheres buscando a independência financeira, $35 \%$, geralmente solteiras.

Quanto às suas expectativas, todas revelam que gostariam de melhorar de vida, seja exercendo uma profissão, como enfermeira ou jornalista, seja tendo um trabalho fixo com carteira assinada, mas não sinalizam como isto pode ser realizado. A impressão é de um discurso pronto que funciona como uma conexão com o mundo do sistema, da compreensão e do compromisso mesmo que apenas em intenção com os princípios normativo e valorativo da sociedade envolvente. Portanto, fica evidente que, embora todas as pessoas, independentemente se na formalidade ou na informalidade, desejem melhorar, não há indicativos de como isto pode ser realizado. Oitenta por cento das mulheres vêem o trabalho como necessidade para a sobrevivência, como uma obrigação ou ainda como responsável para o "progresso", a melhoria de vida da família. Assim, as responsabilidades aumentam à medida que os valores culturais de casamento de longa duração deixam de ser constantes. Afinal, como afirma Bauman (2001), a tendência tem sido a co-habitação e não o matrimônio, o que implica a divisão das responsabilidades.

As opiniões femininas sobre as vantagens do trabalho formal dividem-se entre, de um lado, garantir direitos como o acesso a um plano de saúde que cubra os dependentes, ajustar as necessidades familiares com a carga horária, isto é, ter licenças para acompanhar parentes doentes, geralmente os filhos. Por outro lado, o rigor do cumprimento do horário é um limitador que impede combinar família e trabalho e, ainda, a sensação desagradável de que são tratadas mais como empregadas, no sentido de trabalhadoras domésticas, do que como profissionais. Há uma recusa à passividade frente às humilhações sofridas quando trabalham para terceiros. 
Apesar do esforço para se desdobrarem em inúmeras atividades, há consenso de que o padrão de vida de cada uma melhorou significativamente. $\mathrm{O}$ risco da instabilidade financeira e o pouco tempo de lazer, em nada se comparam ao isolamento da marginalização da mulher dependente, financeira, moral e socialmente. $O$ trabalho na rua permitiu alargar os laços sociais com novas amizades, maior comunicação com outras pessoas, mais informações, gerando um vínculo social mais estável, mais sólido e fortalecendo o indivíduo e a comunidade.

Para estas mulheres a satisfação advém da harmonia familiar, do resultado financeiro do trabalho, do apoio dos amigos e parentes, de suprir as necessidades dos filhos, de estreitar os laços sociais com a ajuda mútua. Esta é uma forma de liberdade gozada através do trabalho. É neste contexto que os amigos são conquistados e mantidos, promovendo uma segurança no que concerne ao apoio direto e imediato das pessoas. Há um tom de desprezo quando se referem à impessoalidade das relações estabelecidas com instituições formais. Por exemplo, poder levar o filho para o trabalho, transformar a parte inferior do balcão em local de descanso, não ter pessoas controlando seus movimentos, conversar franca e espontaneamente com seus vizinhos de trabalho ou clientes, liberdade de negociar preços e serviços, são todos fatores importantíssimos para o bom desempenho na informalidade, pois permitem estabelecer um tipo de solidariedade baseada no que é familiar a cada um, na lógica do doméstico. Isto é imprescindível para o sucesso, pois é no manuseio desses códigos do capital cultural que a confiança, a familiaridade e a espontaneidade se articulam.

6) Solidariedade

A solidariedade manifesta-se tanto na cooperação familiar, com apoio constante no cuidado com as crianças, na substituição temporária na banca da feira de modo a permitir que o trabalhador se ocupe de outras tarefas inadiáveis, como ir ao médico ou ao banco, fazer compras e resolver problemas de ordem familiar. A alta freqüência com que este tipo de cooperação ocorre, quase que diariamente, indica o vigor dos elos sociais de manutenção do grupo familiar. Este elo é muito forte, com a certeza da substituição por tempo indeterminado em caso de doença. 
Quanto aos colegas, isto é, os outros feirantes cujas bancas estão próximas, a ajuda é de menor compromisso, mais imediata, como controle do roubo, empréstimo de pequenas quantias de dinheiro, ou ainda vigiar a banca enquanto o dono se ausenta para um lanche rápido ou para ir ao banheiro, etc.

Apesar dos riscos e da atenção constante com o tipo de solidariedade que se estabelece no local de trabalho e da dependência do apoio familiar, a avaliação do feirante é de que esta atividade promove a independência financeira, principalmente para os mais jovens e para as mulheres, e o fortalecimento dos vínculos sociais, com as denominadas "amizades novas" que são diariamente construídas. Isto provoca a quebra da rotina e favorece a ampliação da rede de sustentação do grupo.

\section{7) Estado}

Percebem-se como pais e mães de família, que lutam pela sobrevivência e qualidade de vida dos seus dependentes, portanto o papel do Estado deveria ser protegê-los e apoiá-los ao invés de tentar retirá-los de locais públicos ou enviar a fiscalização, tratando-os como ilegais. Vários afirmaram: "Estamos trabalhando honestamente e queremos respeito. Não estamos roubando".

É um campo minado e conflitivo no qual o inesperado pode ocorrer, uma vez que o critério de seletividade para atividades e locais não é determinado por parâmetros de competitividade entre setores ou por uma visão estética da cidade. A maioria dos 120 entrevistados (70\%) não se intimida com a ação do Estado, o que resulta, inclusive, na expansão da informalidade. Embora ferindo a lei, é um segmento que tem crescido com o apoio e o respaldo da sociedade civil, consumidora em potencial, que legítima a situação desses trabalhadores, cujo poder advém do reconhecimento que Ihes é concedido por seus fregueses. Esse poder intimida a ação dos fiscais, que tende a ser repressora, e do governo que se vê obrigado a negociar, modificando seu propósito de eliminar para o de realocar. Mais uma vez fica evidente o confronto entre dois discursos, o do Estado que procura controlar e empurrar para a periferia, e o dos trabalhadores informais que procuram se apropriar dos espaços centrais e conquistar clientes. 
Esse poder emana, também, do respaldo dos vínculos sociais daqueles sujeitos que apontam a família, os vizinhos e os amigos como grandes incentivadores. Aceitam a informalidade e se beneficiam dela. Como conseqüência, a representação é construída em função de uma rede de possibilidades de materializar a sobrevivência e a manutenção da qualidade de vida familiar, de promover a autonomia individual, de ter o reconhecimento dos consumidores, de favorecer a circulação de capital e de mercadorias em segmentos mais desfavorecidos, de afrouxamento do rigor da lei, e de sustentação moral do grupo de convívio. Todos estes elementos indicam que esta representação é um processo coletivo, que oferece conforto ao trabalhador e força para a resistência às normas instituídas.

Essa situação complexa faz com que o trabalhador informal encare sua atividade para além das relações de troca. Subentendese ali, a força da relação entre os homens, que procuram ordenar o seu meio e viabilizar sua existência. Nesse contexto, o Estado, como poder repressor, que ignora esta realidade ou trata-a como algo residual, não logra êxito na construção de uma sociedade central, unificada com um projeto coletivo compartilhado. Para $60 \%$ dos entrevistados, o Estado, com o qual convivem diuturnamente, é marcado pela ingênua posição de manter o rigor sem considerar a possível convergência de interesses individuais em um interesse geral pelo fato de ignorar ou ser imparcial às particularidades dos sujeitos sociais. Quando alguns trabalhadores do informal externam uma imagem favorável do Estado, estão de fato referindose à confiança em políticos que se prontificaram na luta pelo reconhecimento e valorização do trabalhador como autônomo, com direito a um processo de regulação diferenciado. Os demais $40 \%$ dos respondentes não manifestaram opiniões acerca do governo, demonstrando dificuldade em construir um discurso sobre seu lugar social enquanto sujeitos que vivem no limbo do direito e, ao mesmo tempo, sendo alvo de sanções por infringir regras sociais.

\section{8) Expectativas}

Os projetos para o futuro estão voltados incondicionalmente para melhores condições de vida e trabalho, tanto para si quanto para seus familiares. O objetivo último é a idéia da felicidade que 
se realiza pela concretização de algumas metas. De um lado, a vontade de ter um empreendimento formalizado, o que significa um salto para a inserção social, a garantia de crédito, a legitimidade da atividade e o reconhecimento social, gerando status. De outro, o desejo de qualificação profissional pela conclusão dos estudos, um dia abandonados, para a inserção, geralmente precoce, no mercado de trabalho. Estes sonhos são enfraquecidos pela demonstração de desilusão com as possibilidades de realizá-los, posto que a realidade do mercado de trabalho brasileiro não permite criar expectativas para o futuro.

\section{À guisa de conclusão}

O discurso que emerge das falas dos trabalhadores em informalidade desvenda uma certa precisão de suas ações, cujo objetivo precípuo tem sido permitir a sobrevivência e, mais importante, favorecer o fortalecimento dos elos familiares e comunitários. Para que isto se realize, a flexibilidade torna-se indispensável. Organizar o trabalho, seguindo de perto a lógica do doméstico, com apoio incondicional de parentes ou pela troca de favores entre vizinhos transferidos para a estrutura do trabalho, indica que estes trabalhadores estão mais atentos às vantagens das atividades e dos locais onde os estabelecimentos são montados, do que de intenção real de formalizar os empreendimentos. Isto porque não identificam o trabalho formal como solução para as dificuldades financeiras, sociais e familiares que enfrentam. Este se constitui como uma opção, na qual terão que se sujeitar aos critérios burocráticos e impessoais de administrar e combinar diferentes atividades, quais sejam, do cuidado concomitante do espaço doméstico e do mundo do trabalho.

Contam com a cumplicidade tática dos consumidores e dos elos familiares para manterem a situação. Isto sinaliza para o balizamento desses sujeitos sobre seu espaço de atuação e vivência como local de enfrentamentos diversos e cuja resolução deriva da leitura que fazem sobre o mercado e a cidade. As alternativas ganham vivacidade nas práticas discursivas. Assim, na avaliação que fazem da realidade não identificam o trabalho formal como solução, mas como mais uma opção. As decisões sobre a atividade ocupacional 
são determinadas por condições particulares de escolaridade, de rendimento auferido, de estrutura familiar e do impacto psicológico e físico das tensões diárias.

O sustentáculo discursivo para suas ações está no significado e valor do trabalho como atividade inerente ao próprio homem e a única forma de se construir a dignidade e a identidade social, principalmente para aqueles que não possuem o conforto de uma estrutura familiar abastada e cujo lastro favoreça a inserção em empregos bem remunerados. A idéia do emprego está invariavelmente vinculada à idéia de salário fixo que propicie uma excelente qualidade de vida. Esta distinção aparece quase sempre na comparação entre "eles, os ricos que ganham muito, e nós, os trabalhadores que ralam todo dia". Assim, identificam o que fazem como um bico, um quebra-galho, uma ocupação que tem por referência a distância do exercício de uma profissão cuja base assenta-se em anos de escolaridade.

Detestam o isolamento provocado pelo processo de polinucleamento que promove o sentimento de diáspora social e econômica. Para combater este incomodo apoiam-se na idéia de flexibilização entendida como afrouxamento das normas e, portanto, legitimação da informalidade. Para realizar seus projetos apropriamse da cidade como um espaço aberto do qual podem se beneficiar. Os vestígios dessa realidade aparecem na regionalização dos sentidos construídos como confronto simbólico que coloca em evidência o desejo de quebrar a lógica da desigualdade baseada na renda.

Chamam a atenção para sua situação, que não é inusitada, posto que está inscrita na história brasileira, mas ganha evidência com a reestruturação produtiva, não pelos que nunca entraram no mercado formal, mas pelos que perderam seus postos de trabalho. Rompem assim, o vazio instaurado entre o instituído e o vivenciado inaugurado com a reestruturação produtiva. A novidade está no fato agora de que a sociedade é obrigada a vê-los e ouvi-los como integrados ao sistema. Destaca-se aqui que este reconhecimento não é aceito por eles sob a condição de se formalizarem, visto que desejam que seus critérios e parâmetros de negociação sejam aceitos pelo sistema, porque sabem que a concepção universalista de direitos e deveres pesa mais contra as peculiaridades das situações cotidianas, onde a solidariedade vale mais que as regras sociais. Afinal, é na informalidade que os obstáculos sociais e econômicos são gerenciados e resolvidos. 
A historicidade desta rebeldia, qual seja, o processo novo de romper amarras, está fortemente vinculada ao processo histórico de perdas sociais, expressas tanto nos valores que norteiam os indivíduos, quanto no que está disponibilizado hoje em termos de códigos de comunicação. Símbolo de situação ambígua que provoca relações de conflito sobre o campo da tradição e do novo. Assim, enquanto um grupo jamais entrou no jogo da formalidade outro é forçado a romper as amarras com o sistema normativo, o qual está cada vez mais distante e coercitivo.

A dinâmica da espacialidade, que combina segregação e apropriação do centro, indica que a cidade esta separada em dois mundos, em duas dimensões discursivas e em dupla organicidade e, ao mesmo tempo, faz emergir o modo como esta desigualdade fortalece o sentimento comunitário dos segregados alojados nas cidades-satélites, permitindo que códigos sejam criados e recriados. O resultado é a manifestação dos desvios da grande massa das camadas de baixa renda, naturalizando sua presença em áreas nobres. Isto é revelador de como o ritmo que vai marcando o status, denunciando a desigualdade e trazendo para o plano do real o confronto entre o projeto das pessoas e o projeto arquitetônico, dá visibilidade ao modo como o recentramento do território ocorre.

Considerando-se o âmbito da história cultural, a informalidade, com suas permanências e temporalidades, utiliza e improvisa, cria códigos e símbolos que servem como denúncia da segregação social e do projeto social que conduz à incerteza e à insegurança. Assim, agregados em torno da idéia de trabalho estruturam suas vidas e sedimentam os vínculos sociais, substrato da vida em sociedade. Afinal, como afirma Lessa (1999, p. 25) "o ato de trabalho passa a ser também (mas não apenas) uma relação de poder entre os homens".

\section{Bibliografia}

BAUMAN, Kygmunt. Modernidade líquida. Rio de Janeiro: Jorge Zahar, 2001.

BURSZTYN, Marcel; ARAÚJO, Carlos Henrique. Da utopia à exclusão: vivendo nas ruas de Brasília. Rio de Janeiro: Garamond; Brasília: CODEPLAN, 1997. 
CASTEL, Robert. De l'exclusion comme état à la vulnérabilité comme processus. In: AFFICHARD, Joëlle; FOUCAULD, Jean-Baptiste de (Orgs.). Justice sociale et inégalités. France: Éditions Esprit, 1992. p.135-148.

CASTORIADIS, Cornelius. A instituição imaginária da sociedade. Rio de Janeiro: Paz e Terra, 1982.

DALBOSCO, Eduardo. O trabalho informal no Brasil: análise, conceito, pesquisa e impacto social. Brasília, 2000. Dissertação (Mestrado em Política Social) - UnB.

CERTEAU, Michel de. A invenção do cotidiano: 1 - artes de fazer. Petrópolis (RJ): Vozes, 1994.

FIREY, Walter. Sentimiento y simbolismo como variables ecológicas. In: THEODORSON, G. A. Estudios de ecología humana. Barcelona: Editorial Labor, 1974. p. 417-432.

HELLER, Agnes. O cotidiano e a história. 6.ed. São Paulo: Hucitec, 2000.

LARANGEIRA, Sônia M. Guimarães. Realidade do trabalho ao final do século XX. Ser Social, Brasília, n. 5, p. 23-44, 1999.

LAUTIER, Bruno. L'économie informelle dans lê tiers monde. Paris: La Découverte, 1994.

LESSA, Carlos. Auto-estima e desenvolvimento social. Rio de Janeiro: Garamond, 2000.

MAFFESOLI, Michel. A transfiguração do político: a tribalização do mundo. Porto Alegre: Sulinas, 1997.

MAFFESOLI, Michel. No fundo das aparências. Petrópolis (RJ): Vozes, 1996.

ORLANDI, Eni P. Tralhas e troços: o flagrante urbano. In: ORLANDI, Eni P. (Org.). Cidade atravessada: os sentidos públicos no espaço urbano. Campinas (SP): Pontes, 2001. p.9-24.

PAVIANI, Aldo. Brasília: a metrópole em crise: ensaios sobre urbanização. Brasília: Editora Universidade de Brasília, 1989.

PIUBELLI. Luiza Alessandra Pessoa. Movimento Social por moradia e o governo democrático e popular no DF. Brasília, 2001. Dissertação (Mestrado) - UnB.

REIMANN, Marcos Francisco. Cidadania e contratos atípicos de trabalho: as políticas sociais e o ordenamento do trabalho. Brasília, 2000. Dissertação (Mestrado em Política Social) - UnB.

SEN, Amartya. Desigualdade reexaminada. Rio de Janeiro: Record, 2001.

SENNETT, Richard. A corrosão do caráter: conseqüências pessoais do trabalho no novo capitalismo. Rio de Janeiro: Record, 1999. 